\title{
Intentional Long-Term Repeated Insulin Overdosing for 15 years in a 55-year Old Male with Compulsive Personality Traits
}

\author{
HORST J. KOCH \\ Department of Psychiatry and Psychotherapy, Heinrich-Braun-Klinikum, Zwickau, Germany
}

\section{To the Editor,}

Insulin abuse due to compulsive craving for insulin is a rare medical phenomenon [1-3]. Insulin abuse is occasionally observed in the body building scene, in the illegal drug scene or associated with eating disorders, but dependence based on a compulsive disorder has not yet been published [4-6].

A 55-year old male grammar school teacher BMI $30 \mathrm{~kg} / \mathrm{m}^{2}$ - presented with insulin abuse for at least 15 years due to marked social problems. A diabetes type 2 with retinopathy, angiopathy and polyneuropathy, was treated for 30 years. He started overdosing insulin 15 years ago, initially 3 to 4 times a year, then almost twice a month. Concomitantly he increased blood glucose controls up to at least 10 times per day. His wife regularly called for the GP or emergency service, which gradually led to a personal crisis with pending divorce and early retirement.

Apart from the diabetes complications he had a history of hypertension, hyperlipidemia and depressive episodes in the past. He received the following medication: enalapril $10 \mathrm{mg}$ bid, HCT 25 $\mathrm{mg}$ mane, metoprolol $47.5 \mathrm{mg}$ bid. Insulin lisproR was applied using a pump system for 4 years (Medtronic Minimed Paradigm). Clinical examination showed scars after partial amputation of the left toe and gluteal syringe abscesses, gynecomastia and varicosis. The neurological findings revealed hypoesthesia, hypoalgesia as well as thermanesthesia of the feet. Clinical laboratory was quite normal with the exception of slightly elevated leucocytes $\left(12.7 * 10^{9} / \mathrm{L}\right)$, creatinine $(176 \mu \mathrm{mol} / \mathrm{L})$ and ASAT $(1.46 \mu \mathrm{mol} / \mathrm{L}), \mathrm{HBA} 1 \mathrm{c}$ was within normal range. Clinical lab controls during the 10 last years, however, showed glucose values down to $1.4 \mathrm{mmols} / \mathrm{L}$.

The psychiatric interview and neuropsychological tests were characterized by a slight depressive and anxious affect with thought confinement to the insulin treatment, insomnia and diabetes including an obvious compulsory component. He denied any suicidal ideas. He described the repeated abuse of insulin as an increasing severe compulsion being incapable to resist to insulin injections. He was classified as abuse with nonpsychoactive drugs (ICD 10 F55.8) and obsessivecompulsive personality disorder (ICD 10 F60.5) and was treated with an SSRI - sertraline starting with $25 \mathrm{mg}$ and incremental escalation up to 200 mg mane including regular supportive psychotherapy appointments. He tolerated sertraline well and was discharged from the ward after 3 weeks time. Up to now (6 months) the patient has had no further insulin overdoses or emergency call-outs.

Although feelings of compulsion did not disappear completely, he successfully reassumed his occupation as a teacher and is very compliant with regard to specialist antidiabetic therapy. He is very content as he could resolve most of his social problems. In conclusion, compulsive insulin abuse may be a very rare clinical challenge that may respond to treatment with SSRIs and psychotherapy.

Corresponding author: Horst J. Koch, MD, PhD, MFPM, DCPSA

Department of Psychiatry and Psychotherapy, Heinrich- Braun-Klinikum, 08060 Zwickau, Germany

E-mail: Horst.koch@hbk-zwickau.de

\section{REFERENCES}

1. WAICKUS CM, DE BUSTROS A, SHAKIL A. Recognizing factitious hypoglycemia in the family practice setting. J Am Board Fam Pract. 1999; 12(2): 133-6.

2. SCHULER G, PETERSEN KG., KHALAF KN., KERP L. Insulin abuse in long-standing IDDM. Diabetes Res Clin Practice. 1989; 6(2): 146-8. 
3. GRAHAM MR, EVANS P, DAVIES B, BAKER JS. AAS, growth hormone, and insulin abuse: psychological and neuroendocrine effects. Therapeutics and Clinical Risk Management. 2008; 4(3): 587-97.

4. EVANS PJ, LYNCH RM. Insulin as a drug of abuse in body building. Br J Sports Med. 2003; 37(4): 356-7.

5. RETSAS S. Insulin abuse by a drug addict. BMJ. 1972; 4(5843): 792-3.

6. MOOSAVI M, KREISMAN S, HALL L. Intentional hypoglycemia to control bingeing in a patient with type 1 diabetes and bulimia nervosa. Can J Diabetes. 2015; 39(1): 16-7.

Received February 2, 2016 